\title{
Deactivation of carotid body chemoreceptors by hyperoxia decreases blood pressure in hypertensive patients
}

\author{
Maciej Sinski ${ }^{1}$, Jacek Lewandowski ${ }^{1}$, Jacek Przybylski ${ }^{2}$, Paweł Zalewski ${ }^{3}$, Bartosz Symonides ${ }^{1}$, \\ Piotr Abramczyk ${ }^{1}$ and Zbigniew Gaciong ${ }^{1}$
}

Previous studies have shown that hyperoxia-induced deactivation of carotid body chemoreceptors reduces sympathetic activity in hypertensive patients but it does not affect blood pressure. The maintenance of blood pressure can be explained by the direct, vasoconstrictive effect of hyperoxia, which offsets diminished sympathetic activity. This study compares the effect of acute hyperoxia on hemodynamic parameters between hypertensive and normotensive subjects. Twelve males with hypertension (age $39.4 \pm 2.4$ years; body mass index $27.4 \pm 1.1 \mathrm{~kg} \mathrm{~m}^{-2}$ ) and 11 normotensive males (age $39.9 \pm 2.7$ years; body mass index $25.4 \pm 0.7 \mathrm{~kg} \mathrm{~m}^{-2}$ ) received, via non-rebreathing mask ventilation, ambient air, followed by $100 \%$ oxygen for $20 \mathrm{~min}$. The stroke volume, heart rate, cardiac output, blood pressure, total peripheral resistance, respiratory rate, baroreceptor control of heart rate and oxygen saturation were recorded continuously. Several 30 s periods were analyzed before, during and after inducing hyperoxia. At baseline, the hypertensive subject's blood pressure was higher and their baroreflex control of heart rate was lower when compared with the normotensive control group. After the first $30 \mathrm{~s}$ of hyperoxia, systolic, diastolic and mean blood pressures, as well as the total peripheral resistance, decreased significantly in hypertensives but not in normotensives. After 20 min of $100 \%$ oxygen ventilation, systolic and mean blood pressures and total peripheral resistance was increased in hypertensive patients, and the cardiac output and stroke volume had decreased in both groups. The results of this study confirm that deactivation of carotid body chemoreceptors can acutely decrease blood pressure in humans. Hypertension Research (2014) 37, 858-862; doi:10.1038/hr.2014.91; published online 8 May 2014

Keywords: baroreflex; blood pressure; carotid body chemoreceptors; hyperoxia

\section{INTRODUCTION}

Pharmacotherapy in hypertension aims to improve the control of blood pressure (BP) and reduce cardiovascular risk. However, only $30 \%$ of hypertensive patients have good BP control, and $50 \%$ of those treated discontinue their therapy after 1 year. ${ }^{1-4}$ To improve BP control and reduce cardiovascular mortality, newer nonpharmacological methods of hypertension treatment have been introduced to target the autonomic nervous system. These include kidney denervation and baroreceptor stimulation. The rationale for both methods are based on the observed increased sympathetic activity in hypertensive patients. ${ }^{5-9}$ An increased basal sympathetic tone is not only an attribute of young and borderline hypertensives ${ }^{9,10}$ but it is also present in subjects with moderate and severe hypertension. ${ }^{6,11-13}$ Furthermore, an elevated sympathetic drive correlates with BP values, ${ }^{6}$ which may postulate a direct causal relationship between the two. ${ }^{6,12}$ The carotid body chemoreceptors contribute significantly to the activity of the autonomic nervous system and its increased activity in hypertensive patients is well documented. It may even be worth to consider what extent the carotid body chemoreceptors have in the pathogenesis of primary hypertension. ${ }^{13-16}$ Animal model studies have already demonstrated that surgical chemoreceptor deactivation decreases BP and prevents the development of hypertension. ${ }^{17}$

Our previous study showed that the deactivation of carotid body chemoreceptors, by inducing hyperoxia, reduces sympathetic activity in hypertensive subjects but not in the normotensive individuals. ${ }^{18}$ However, we did not observe any significant changes in BP between the two groups. Hyperoxia induces direct vasoconstriction and it is possible that this effect offsets the drop of BP related to chemoreceptor deactivation. ${ }^{18}$ The latency of direct vasoconstriction caused by hyperoxia is much longer than the latency of deactivating arterial chemoreceptors, and we have taken this into account while preparing the methodology of our study (see below). It should be expected that there will be a decrease in BP during the early stage of hyperoxia.

${ }^{1}$ Department of Internal Medicine, Hypertension and Vascular Diseases, Medical University of Warsaw, Warsaw, Poland; ${ }^{2}$ Department of Biophysics and Physiology, Medical University of Warsaw, Warsaw, Poland and ${ }^{3}$ Department of Hygiene and Epidemiology, Faculty of Health Sciences Ludwik Rydygier Collegium Medicum in Bydgoszcz Nicolaus Copernicus University in Torun, Bydgoszcz, Poland

Correspondence: Dr J Lewandowski, Department of Internal Medicine, Hypertension and Vascular Diseases, Medical University of Warsaw, Banacha 1a, 02-097 Warsaw, Poland. E-mail: j_lewandowski@yahoo.com

Received 29 December 2013; revised 8 March 2014; accepted 27 March 2014; published online 8 May 2014 
The purpose of our study was to determine the acute effect of hyperoxia on BP and other hemodynamic parameters in hypertensive and normotensive subjects.

\section{METHODS}

\section{Subjects}

Twelve patients with essential hypertension (age $39.4 \pm 2.3$ years; body mass index $27.4 \pm 1.0$ ) and 11 normotensive males (age $39.9 \pm 2.7$ years; body mass index $25.4 \pm 0.7$ ) were invited for assessment in our laboratory. Six of the patients with hypertension followed the antihypertensive regimens: two patients were being treated with a combination of perindopril and indapamide, two with a combination of perindopril and amlodipine and two with amlodipine only. The treatments were unaltered for at least 4 weeks before conducting our study. The remaining 6 patients with hypertension and the 11 control subjects were not taking medications. All patients underwent routine diagnostic evaluation for hypertension in our department clinic. Patients with grade 3 hypertension, secondary forms of hypertension, including obstructive sleep apnea syndrome, diabetes and arrhythmias, were excluded from the study. Other exclusion criteria included chronic obstructive pulmonary disease, asthma, congenital cyanotic heart disease and active smoking. The Ethical Committee of the Medical University of Warsaw accepted the study protocol. All participants provided informed consent.

\section{Study procedures}

All subjects were studied at midday, in a quiet room, in supine position. The room temperature was kept constant at $20-21^{\circ} \mathrm{C}$. Subjects were instructed to have a light breakfast in the morning, and those on hypertensive therapy were asked to take their routine morning medication. All patients underwent baseline recordings (as defined below) for $10 \mathrm{~min}$ before the placement of a non-rebreathable mask. The subjects were then started on ventilating $21 \%$ oxygen for 10 min by mask, followed by 20 min of $100 \%$ oxygen ventilation to induce hyperoxia. This was followed by a 10 -min recovery period of $21 \%$ oxygen for $10 \mathrm{~min}$. The flow rate through the non-rebreathable mask was constant throughout the study at $101 \mathrm{~min}^{-1}$. The subjects were blinded to the type and percentage of gas they were inspiring. Oxygen saturation $\left(\right.$ sat $\left.\mathrm{O}_{2}\right)$ and end tidal $\mathrm{CO}_{2}$ and respiratory rate (RR) were monitored through the study (CapnoCheck Plus, Smith Medical International, Watford, Herts, UK).

\section{Assessment of hemodynamic responses}

All measurements were performed with a task force monitor (CNSystems Medizintechnik, Graz, Austria). The task force monitor application is an automated and computed beat-to-beat analyzer, providing heart rate (HR) (electrocardiogram signal), oscillometric and noninvasive continuous BP measurements (photoelectric vascular unloading method-systolic BP (SBP) and diastolic BP (DBP)) and continuous measurement of cardiac output (CO), stroke volume (SV) and total peripheral resistance (TPR) based on impedance cardiography. The task force monitor facilitates continuous (beat-to-beat), reliable and reproducible measurements of hemodynamic parameters. ${ }^{19-22}$ Baroreflex control of the HR was also calculated using the task force monitor system and the sequence method with signals was derived from continuous BP measurement and electrocardiogram tracing. Briefly, the sequence method detects sequences of SBP increases or decreases, accompanied by prolongation or shortening of electrocardiogram RR intervals, respectively. If three or more consecutive beats show an increase (or decrease) in SBP ( $\geqslant 1 \mathrm{~mm} \mathrm{Hg}$ per beat), a BP ramp is detected. If the BP ramp is accompanied by an increase (or decrease) of $\geqslant 4 \mathrm{~ms}$ in the RR interval, a baroreceptor sequence is detected. In our study, we used combined up and down sequence count.

\section{Statistics}

During the session the subject's hemodynamic parameters were continuously recorded. Each parameter was analyzed six times throughout the study, using the average values over 30 s periods ( $\mathrm{P}-1, \mathrm{P} 0, \mathrm{P} 1, \mathrm{P} 2, \mathrm{P} 3$ and $\mathrm{P} 4)$. The decision to use $30 \mathrm{~s}$ periods was to ascertain early hemodynamic response to hyperoxiainduced carotid body deactivation..$^{23,24} \mathrm{~A}$ timeline representing the period of analyses is presented in Figure 1. P-1 was recorded during the last $30 \mathrm{~s}$ of normal room air breathing before mask ventilation. P0 was the baseline and it

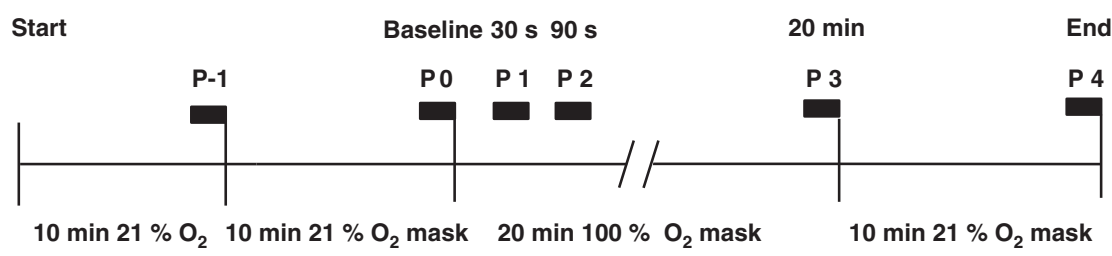

Figure 1 Scheme of study periods and data acquisition.

Table 1 Effect of $100 \% \mathrm{O}_{2}$ breathing on the recorded parameters in hypertensive patients and normotensive controls

\begin{tabular}{|c|c|c|c|c|c|c|c|c|c|}
\hline \multirow{2}{*}{$\begin{array}{l}\text { Group } \\
\text { Parameter }\end{array}$} & \multicolumn{4}{|c|}{ Hypertensive patients } & \multicolumn{4}{|c|}{ Normotensive controls } & \multirow{2}{*}{$\frac{\text { Group vs. time }}{\text { P-value }}$} \\
\hline & Baseline & $30 s$ & $90 \mathrm{~s}$ & $20 \mathrm{~min}$ & Baseline & $30 s$ & $90 s$ & $20 \mathrm{~min}$ & \\
\hline $\mathrm{SBP}(\mathrm{mm} \mathrm{Hg})$ & $127 \pm 2.7$ & $123 \pm 2.4$ & $124 \pm 2.4$ & $129 \pm 3.0$ & $111 \pm 2.9^{a}$ & $112 \pm 2.6$ & $114 \pm 2.6$ & $113 \pm 3.0$ & 0.017 \\
\hline $\mathrm{DBP}(\mathrm{mm} \mathrm{Hg})$ & $83 \pm 2.1$ & $80 \pm 2.9^{b}$ & $81 \pm 2.5$ & $86 \pm 2.4$ & $71 \pm 24^{a}$ & $72 \pm 2.6$ & $73 \pm 2.8$ & $75 \pm 2.0$ & 0.20 \\
\hline $\mathrm{MBP}(\mathrm{mm} \mathrm{Hg})$ & $98 \pm 2.4$ & $94 \pm 2.7$ & $95 \pm 2.9$ & $100 \pm 3.6$ & $84 \pm 1.9^{a}$ & $86 \pm 1.8$ & $87 \pm 1.6$ & $88 \pm 2.0$ & 0.049 \\
\hline $\mathrm{HR}$ (beat $\mathrm{min}^{-1}$ ) & $70 \pm 2.5$ & $67 \pm 2.4$ & $68 \pm 2.6$ & $67 \pm 2.6$ & $67 \pm 2.7$ & $61 \pm 2.6$ & $61 \pm 3.8$ & $65 \pm 2.6$ & 0.43 \\
\hline TPR dyne $\cdot \mathrm{scm}^{-5}$ ) & $1490 \pm 125$ & $1343 \pm 130$ & $1429 \pm 151$ & $1644 \pm 151$ & $1328 \pm 163$ & $1453 \pm 200$ & $1411 \pm 159$ & $1435 \pm 159$ & 0.039 \\
\hline SV (ml) & $77 \pm 7.0$ & $77 \pm 7.2$ & $77 \pm 6.8$ & $72 \pm 6.2$ & $86 \pm 8.2$ & $89 \pm 8.4$ & $87 \pm 7.9$ & $82 \pm 7.2$ & 0.92 \\
\hline $\mathrm{CO}\left(I \mathrm{~min}^{-1}\right)$ & $5.4 \pm 0.5$ & $5.2 \pm 0.5$ & $5.2 \pm 0.5$ & $4.8 \pm 0.4$ & $5.8 \pm 0.7$ & $5.3 \pm 0.6$ & $5.5 \pm 0.6$ & $5.5 \pm 0.5$ & 0.39 \\
\hline Sat $\mathrm{O}_{2}(\%)$ & $96 \pm 0.4$ & $98 \pm 0.2^{c}$ & $98 \pm 0.3^{c}$ & $98 \pm 0.3^{c}$ & $96 \pm 0.4$ & $98 \pm 0.3^{c}$ & $98 \pm 0.3^{c}$ & $98 \pm 0.2^{c}$ & 0.27 \\
\hline BRS ( $m s m m \mathrm{Hg}^{-1}$ ) & $11 \pm 1.8$ & $13 \pm 2.1$ & $13 \pm 2.1$ & $12 \pm 2.1$ & $17 \pm 1.7^{a}$ & $19 \pm 2.0$ & $20 \pm 2.0$ & $19 \pm 2.0$ & 0.52 \\
\hline RR (breaths $\min ^{-1}$ ) & $13 \pm 0.9$ & $11 \pm 0.7$ & $11 \pm 0.7$ & $12 \pm 0.7$ & $13 \pm 0.9$ & $12 \pm 0.8$ & $11 \pm 0.7$ & $14 \pm 0.7$ & 0.37 \\
\hline
\end{tabular}

Abbreviations: BRS, baroreflex control of the heart rate; DBP, diastolic blood pressure; HR, heart rate; MBP, mean blood pressure; sat $\mathrm{O}_{2}$, oxygen saturation; $\mathrm{SBP}$, systolic blood pressure; TPR, total peripheral resistance.

a $P<0.05$ as compared with hypertensive patients.

a $P<0.05$ as compared with hypertensive
${ }^{\mathrm{b}} P=0.043$ as compared with baseline.

c $P<0.05$ as compared with baseline. 
Table 2 Effect of the respiratory mask placement on the recorded parameters in hypertensive patients and normotensive controls

\begin{tabular}{|c|c|c|c|c|c|}
\hline \multirow{2}{*}{$\begin{array}{l}\text { Group } \\
\text { Parameter }\end{array}$} & \multicolumn{2}{|c|}{ Hypertensive patients } & \multicolumn{2}{|c|}{ Normotensive controls } & \multirow{2}{*}{$\frac{\text { Group vs. tim }}{\text { P-value }}$} \\
\hline & Baseline without mask & Baseline with mask & Baseline without mask & Baseline with mask & \\
\hline $\mathrm{SBP}(\mathrm{mm} \mathrm{Hg})$ & $129 \pm 2.7$ & $127 \pm 2.7$ & $113 \pm 2.8^{*}$ & $111 \pm 2.9^{*}$ & NS \\
\hline $\mathrm{DBP}(\mathrm{mm} \mathrm{Hg})$ & $86 \pm 2.2$ & $83 \pm 2.1$ & $75 \pm 2.3^{*}$ & $71 \pm 24^{*}$ & NS \\
\hline $\mathrm{MBP}(\mathrm{mm} \mathrm{Hg})$ & $100 \pm 2.4$ & $99 \pm 2.2$ & $88 \pm 2.0 *$ & $87 \pm 1.8^{*}$ & NS \\
\hline HR (beats $\min ^{-1}$ ) & $70 \pm 3.7$ & $70 \pm 2.5$ & $71 \pm 3.4$ & $67 \pm 2.7$ & NS \\
\hline TPR (dyne $\cdot \mathrm{scm}^{-5}$ ) & $1450 \pm 130$ & $1441 \pm 154$ & $1394 \pm 174$ & $1328 \pm 163$ & NS \\
\hline SV $(\mathrm{ml})$ & $76 \pm 6.7$ & $77 \pm 7.0$ & $81 \pm 9.2$ & $86 \pm 8.2$ & NS \\
\hline $\mathrm{CO}\left(1 \mathrm{~min}^{-1}\right)$ & $5.5 \pm 0.5$ & $5.4 \pm 0.5$ & $5.7 \pm 0.7$ & $5.8 \pm 0.7$ & NS \\
\hline Sat $\mathrm{O}_{2}(\%)$ & $95 \pm 0.5$ & $96 \pm 0.4$ & $96 \pm 0.5$ & $96 \pm 0.4$ & NS \\
\hline
\end{tabular}

Abbreviations: $\mathrm{CO}$, cardiac output; DBP, diastolic blood pressure; HR, heart rate; MBP, mean blood pressure; sat $\mathrm{O}_{2}$, oxygen saturation; SV, stroke volume; TPR, total peripheral resistance. ${ }^{*} P<0.05$ as compared with hypertensives.
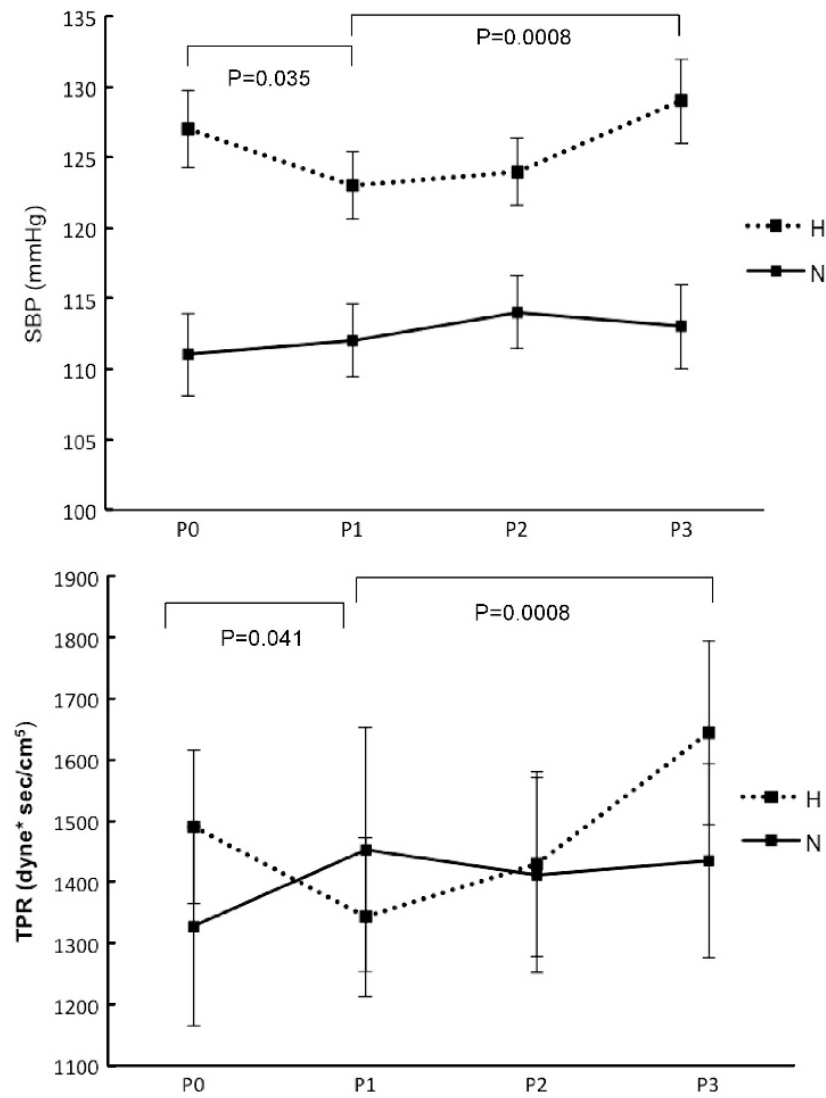

Figure 2 Changes over time in systolic blood pressure (SBP) and total peripheral resistance (TPR) as a result of $100 \% \mathrm{O}_{2}$ breathing in the group of hypertensive patients $(\mathrm{H})$ and normotensive controls $(\mathrm{N})$ are shown.

was recorded during the last $30 \mathrm{~s}$ of breathing $21 \%$ oxygen by mask. P1, P2 and P3 were recorded during the interval at which subjects were ventilated with $100 \%$ oxygen by mask, and correspond to the periods between $30-60,90-120$ and the last $30 \mathrm{~s}$ before the $20 \mathrm{~min}$ mark, respectively. The subjects returned to breathing $21 \%$ oxygen by mask and P-4 was recorded during the last $30 \mathrm{~s}$ of this recovery phase. The baseline values in hypertensive patients and normotensive subjects were compared using unpaired $t$-tests (two-tailed). The effects of hyperoxia were examined by repeated measurements of analysis of variance, with the time periods (P0, P1, P2 and P3) and groups (hypertensives and normotensives) as the within factor and between factor, respectively. The $P$-values were obtained post hoc using the near-infrared Fisher's test. Our primary variable was time vs. group interaction for SBP and

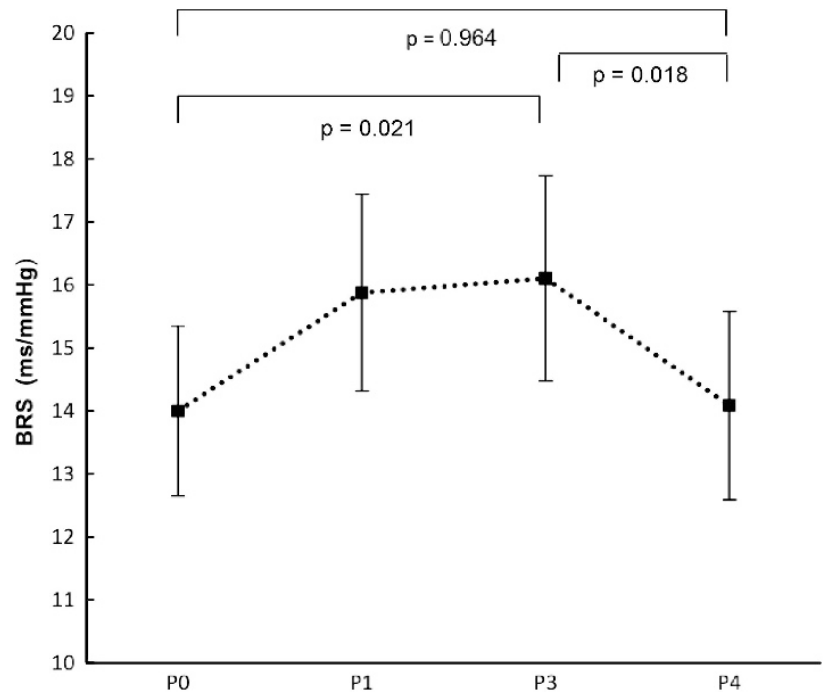

Figure 3 Changes in the baroreflex control of the heart rate (BRS) as a result of $100 \% \mathrm{O}_{2}$ breathing and change to $21 \% \mathrm{O}_{2}$ breathing in all study participants are shown.

TPR during hyperoxic stimuli. The study group calculation was based on extrapolating the previous results derived from a study of 12 hypertensive subjects and 11 normotensive individuals. ${ }^{18}$ Within that report, significant differences in muscle sympathetic nerve activity due to deactivation of carotid body chemoreceptors with hyperoxia was documented. All data are expressed in mean values \pm s.e.m. Statistical analysis was performed using Statistica 10 software (StatSoft, Tulsa, OK, USA).

\section{RESULTS}

The baseline values of SBP, DBP, mean BP (MBP) and baroreflex control of the HR in hypertensive patients differed significantly from those in normotensive subjects (Table 1). There were no differences with respect to age, body mass index, SV, CO, HR, TPR, sat $\mathrm{O}_{2}$, end tidal $\mathrm{CO}_{2}$ and $\mathrm{RR}$ between groups.

When comparing either groups SBP, DBP, SV, TPR, $\mathrm{CO}$, sat $\mathrm{O}_{2}$, end tidal $\mathrm{CO}_{2}$ and RR during P0 (baseline) and P-1 (normal breathing), there were no differences (Table 2).

For the primary variable (interaction group $v s$. time), breathing $100 \%$ oxygen resulted in a significant reduction in SBP, MBP and TPR in hypertensive patients compared with normotensive subjects (Table 1 and Figure 2). Posttest analysis additionally revealed a decrease in DBP between P0 and P1 (Table 1). RR decreased and sat 
$\mathrm{O}_{2}$ increased in both groups proportionally in response to hyperoxia (Table 1). In contrast to normotensive subjects, SBP, MBP and TPR significantly increased in hypertensive patients between P1 and P3 (Figure 2), as compared with normotensive subjects.

Between P3 and $10 \mathrm{~min}$ after the discontinuation of ventilating $100 \% \quad \mathrm{O}_{2}$ (i.e. P4), there was a decrease in SBP $(129 \pm 3.0$ vs. $125 \mathrm{~mm} \mathrm{Hg} \pm 3.4, P=0.014)$ and TPR $(1644 \pm 151$ vs. $1491 \pm 135$ dyne $\left.\cdot \mathrm{s} \mathrm{cm}^{-5}, P=0.047\right)$ and an increase in RR $(12 \pm 0.7$ vs. $15 \pm 0.8$ breaths $\min ^{-1}, P=0.002$ ) in the hypertensive group only. In both groups, sat $\mathrm{O}_{2}$ decreased between these periods.

\section{DISCUSSION}

The results of our study show that deactivating carotid body chemoreceptors in hypertensive patients through hyperoxic ventilation decreases the SBP acutely, with an accompanying reduction of TPR (Figure 2). In animal models, short periods of hyperoxia, lasting 5-60s, reduce tidal volume and respiratory frequency with an accompanying decrease in $\mathrm{BP}$ and HR. Additionally, chemoreceptor resection abolished the effect of deactivating the carotid body. ${ }^{23}$ Similar reductions in BP and TPR owing to transient hyperoxic ventilation were also observed in hypertensive patients. ${ }^{24,25}$

A recent study performed by Abdala et al. ${ }^{17}$ investigated the resection of carotid bodies and its effect on reducing BP in rats, and it is now hypothesized that the carotid bodies might be a target for treatment procedures in hypertension. ${ }^{26-28}$ Moreover, there is one case study that has already documented the therapeutic effective of carotid body resection in a patient with heart failure. ${ }^{29}$ Our study adds new data and confirms that the inhibition of a sympathetic carotid body drive may reduce BP.

Within our study, the observed effect on SBP and TPR was short lasting (Figure 2), and during the $20 \mathrm{~min}$ of hyperoxic ventilation, both the TPR and SBP rebounded as patients continued to inspire $100 \% \mathrm{O}_{2}$. Our results are consistent with previously published data showing that long exposure to hyperoxia may influence systemic vascular resistance, $\mathrm{SV}$ and $\mathrm{BP} .^{30,31}$

One peculiarity arose as to why the DBP did not decrease to the same significant extent as SBP; and additionally, after only $60 \mathrm{~s}$ of acute hyperoxia, there was significant decrease in DBP in the hypertensive group that was not seen in the normotensive subjects (Table 1). When all periods of hyperoxia were considered, the difference between groups disappeared. It is plausible that DBP is a more sensitive marker of hyperoxia-induced vasoconstriction, which could explain why the summary result of carotid body chemoreceptor deactivation and peripheral action of hyperoxia at first influences DBP values and later SBP values.

There were no differences in CO, SV, HR and TPR at baseline, although the MBP differed between the hypertensive group and the control group. This difference can be explained by the fact that in patients with hypertension, BP may be generated through an increase in $\mathrm{CO}$ or an increase in TPR, or a combination of both.

While the study participants were inspiring hyperoxic gas, the baroreflex control of the HR increased (Figure 3), confirming previous results that identify a negative feedback between chemoreflex and baroreflex; inhibiting the carotid body tonic activity augments the baroreflex response. ${ }^{17,32-34}$ Surprisingly, it was also found that the withdrawal of the inhibitory stimulus upon the carotid body chemoreceptors resets the baroreflex control of the HR to basal values after $10 \mathrm{~min}$. This suggests that carotid bodies were inhibited as long as hyperoxia was continued (Figure 3), and to our knowledge currently, this may be the first report to identify the time at which interrupting chemoreceptor deactivation restores baroreceptor control of the HR to basal values.

In conclusion, the results of our study confirm that the deactivation of carotid body chemoreceptors does decrease BP. However, owing to hyperoxia-induced vasoconstriction in the periphery, the decrease in $\mathrm{BP}$ is transient. Although the reduction in hypertensive subjects is short-lasting, it does not imply that chemoreceptor deactivation is not effective in reducing BP, rather it implies that hyperoxia as a tool for investigating carotid body inhibition has serious limitations. We emphasize the necessity for further studies and patient testing to determine whether the carotid body chemoreceptor is a safe and effective target for the treatment of hypertension.

\section{ACKNOWLEDGEMENTS}

We thank Drs Sean C Kearney and Małgorzata Symonides for the help in the manuscript preparation. This study was supported by the status found of the Department of Internal Medicine, Hypertension and Vascular Diseases,

Medical University of Warsaw.

1 Sackett DL, Haynes RB, Gibson ES, Hackett BC, Taylor DW, Roberts RS, Johnson AL. Randomised clinical trial of strategies for improving medication compliance in primary hypertension. Lancet 1975; 1: 1205-1207.

2 Costa FV. Compliance with antihypertensive treatment. Clin Exp Hypertens 1996; 18 : 463-472.

3 Burt VL, Whelton P, Roccella EJ, Brown C, Cutler JA, Higgins M, Horan MJ, Labarthe D. Prevalence of hypertension in the US adult population. Results from the Third National Health and Nutrition Examination Survey, 1988-1991. Hypertension 1995; 25: 305-313.

4 Mapes RE. Physicians' drug innovation and relinquishment. Soc Sci Med 1977; 11: 619-624.

5 Anderson EA, Sinkey CA, Lawton WJ, Mark AL. Elevated sympathetic nerve activity in borderline hypertensive humans. Evidence from direct intraneural recordings. Hypertension 1989; 14: 177-183.

6 Grassi G, Cattaneo BM, Seravalle G, Lanfranchi A, Mancia G. Baroreflex control of sympathetic nerve activity in essential and secondary hypertension. Hypertension 1998; 31: 68-72.

7 Grassi G. Role of the sympathetic nervous system in human hypertension. J Hypertens 1998; 16 (Part 2): 1979-1987.

8 Mark AL. The sympathetic nervous system in hypertension: a potential long-term regulator of arterial pressure. J Hypertens Supp/ 1996; 14: S159-S165.

9 Julius S, Krause L, Schork NJ, Mejia AD, Jones KA, van de Ven C, Johnson EH, Sekkarie MA, Kjeldsen SE, Petrin J, Schmouder R, Gupta R, Ferraro J, Nazzaro P, Weissfeld J. Hyperkinetic borderline hypertension in Tecumseh, Michigan. J Hypertens 1991; 9: 77-84.

10 Vallbo AB, Hagbarth KE, Torebjork HE, Wallin BG. Somatosensory, proprioceptive, and sympathetic activity in human peripheral nerves. Physiol Rev 1979; 59: 919-957.

11 Grassi G. Assessment of sympathetic cardiovascular drive in human hypertension: achievements and perspectives. Hypertension 2009; 54: 690-697.

12 Smith PA, Graham LN, Mackintosh AF, Stoker JB, Mary DA. Relationship between central sympathetic activity and stages of human hypertension. Am J Hypertens 2004; 17: $217-222$.

13 Trzebski A, Tafil M, Zoltowski M, Przybylski J. Increased sensitivity of the arterial chemoreceptor drive in young men with mild hypertension. Cardiovasc Res 1982; 16: 163-172.

14 Tafil-Klawe M, Trzebski A, Klawe J. Contribution of the carotid chemoreceptor reflex to the mechanism of respiratory sinus arrhythmia in young healthy and hypertensive humans. Acta Physiol Pol 1985; 36: 59-64.

15 Przybylski J. Do arterial chemoreceptors play a role in the pathogenesis of hypertension? Med Hypotheses 1981; 7: 127-131.

16 Przybylski J, Trzebski A, Przybyszewski A. Circulatory responses to acute hypoxia in spontaneously hypertensive and normotensive rats. Acta Physiol Pol 1980; 31: 463-468.

17 Abdala AP, McBryde FD, Marina N, Hendy EB, Engelman ZJ, Fudim M, Sobotka PA, Gourine AV, Paton JF. Hypertension is critically dependent on the carotid body input in the spontaneously hypertensive rat. J Physiol 2012; 590 (Part 17): 4269-4277.

18 Sinski M, Lewandowski J, Przybylski J, Bidiuk J, Abramczyk P, Ciarka A, Gaciong Z. Tonic activity of carotid body chemoreceptors contributes to the increased sympathetic drive in essential hypertension. Hypertens Res 2012; 35: 487-491.

19 Fortin J, Habenbacher W, Heller A, Hacker A, Grullenberger R, Innerhofer J, Passath H, Wagner C, Haitchi G, Flotzinger D, Pacher R, Wach P. Non-invasive beat-to-beat cardiac output monitoring by an improved method of transthoracic bioimpedance measurement. Comput Biol Med 2006; 36: 1185-1203. 
20 Parati G, Ongaro G, Bilo G, Glavina F, Castiglioni P, Di Rienzo M, Mancia G. Non-invasive beat-to-beat blood pressure monitoring: new developments. Blood Press Monit 2003; 8: 31-36.

21 Gratze G, Fortin J, Holler A, Grasenick K, Pfurtscheller G, Wach P, Schonegger J, Kotanko P, Skrabal F. A software package for non-invasive, real-time beat-to-beat monitoring of stroke volume, blood pressure, total peripheral resistance and for assessment of autonomic function. Comput Biol Med 1998; 28: 121-142.

22 Gratze G, Rudnicki R, Urban W, Mayer H, Schlogl A, Skrabal F. Hemodynamic and autonomic changes induced by Ironman: prediction of competition time by blood pressure variability. J App/ Physiol 2005; 99: 1728-1735.

23 Zapata P, Larrain C, Rivera MA, Calderon C. Cardiovascular responses to hyperoxic withdrawal of arterial chemosensory drive. Adv Exp Med Biol 2009; 648: 290-297.

24 Izdebska E, Izdebski J, Trzebski A. Hemodynamic responses to brief hyperoxia in healthy and in mild hypertensive human subjects in rest and during dynamic exercise. J Physiol Pharmacol 1996; 47: 243-256.

25 Izdebska E, Izdebski J, Cybulska I, Makowiecka-Ciesla M, Trzebski A. Moderate exercise training reduces arterial chemoreceptor reflex drive in mild hypertension. J Physiol Pharmacol 2006; 57 (Suppl 11): 93-102.

26 McBryde FD, Abdala AP, Hendy EB, Pijacka W, Marvar P, Moraes DJ, Sobotka PA, Paton JF. The carotid body as a putative therapeutic target for the treatment of neurogenic hypertension. Nat Commun 2013; 4: 2395.

27 Paton JF, Ratcliffe L, Hering D, Wolf J, Sobotka PA, Narkiewicz K. Revelations about carotid body function through its pathological role in resistant hypertension. Curr Hypertens Rep 2013; 15: 273-280.
28 Paton JF, Sobotka PA, Fudim M, Engelman ZJ, Hart EC, McBryde FD, Abdala AP Marina N, Gourine AV, Lobo M, Patel N, Burchell A, Ratcliffe L, Nightingale A. The carotid body as a therapeutic target for the treatment of sympathetically mediated diseases. Hypertension 2013; 61: 5-13.

29 Niewinski P, Janczak D, Rucinski A, Jazwiec P, Sobotka PA, Engelman ZJ, Fudim M, Tubek S, Jankowska EA, Banasiak W, Hart EC, Paton JF, Ponikowski P. Carotid body removal for treatment of chronic systolic heart failure. Int J Cardiol 2013; 168 . 2506-2509.

30 Bak Z, Sjoberg F, Rousseau A, Steinvall I, Janerot-Sjoberg B. Human cardiovascular dose-response to supplemental oxygen. Acta Physiol (Oxford) 2007; 191: 15-24.

31 Mak S, Azevedo ER, Liu PP, Newton GE. Effect of hyperoxia on left ventricular function and filling pressures in patients with and without congestive heart failure. Chest 2001; 120: $467-473$

32 Ponikowski P, Chua TP, Piepoli M, Ondusova D, Webb-Peploe K, Harrington D, Anker SD, Volterrani M, Colombo R, Mazzuero G, Giordano A, Coats AJ. Augmented peripheral chemosensitivity as a potential input to baroreflex impairment and autonomic imbalance in chronic heart failure. Circulation 1997: 96: 2586-2594.

33 Paton JF, Boscan P, Pickering AE, Nalivaiko E. The yin and yang of cardiac autonomic control: vago-sympathetic interactions revisited. Brain Res Brain Res Rev 2005; 49: 555-565.

34 Despas F, Lambert E, Vaccaro A, Labrunee M, Franchitto N, Lebrin M, Galinier M, Senard JM, Lambert G, Esler M, Pathak A. Peripheral chemoreflex activation contributes to sympathetic baroreflex impairment in chronic heart failure. $J$ Hypertens 2012; 30: 753-760. 